\title{
PIPE-LINE CURRENTS AND SOIL RESISTIVITY AS INDI- CATORS OF LOCAL CORROSIVE SOIL AREAS
}

\author{
By E. R. Shepard
}

ABSTRACT

The present tendency in the protection of pipe lines against soil corrosion is away from a uniform coating for the entire length of the line and toward the application of coatings selected with respect to the corrosive character of the eoils involved. This calls for a knowledge of varying soil conditionz and a means of locating local corrosive soil areas. Such areas, commonly vermed "hot spote," are prevalent in many types of soils and it is in these regions that pipe lines suffer the greatest deterioration. The location of such corrosive areas is a matter of considerable importance, both with respect to the selection of coatings for new pipe lines and the reconditioning of old ones.

An extensive investigation on a dozen pipe lines ranging from the gulf coast to southern Kansas revealed an apparent correlation between pipe-line currents, soil resistivity, and corrosion. Galvanic currents of measurable magnitudes were found to be flowing on all pipe lines examined. As a rule, lines were found to be collecting current in areas of normal and high soil resistivity and losing current in areas of low resistivity. Many cases of abrupt loss or discharge of current occurred in soils of unusually low resistivity. In such areas the pipe lines were found to be badly corroded.

Although no direct relation was found to exist between electrical resistivity of soils and their corrosiveness, abrupt changes in resistivity and unusually low resistivity were found to be significant with respect to corrosion. Soils having a resistivity of about $500 \mathrm{ohm}-\mathrm{cm}$ or less were invariably found to be highly corrosive. A better relation between resistivity and corrosiveness exists in alkaline than in acid soils.

The technique of surveying pipe lines for galvanic currents is discussed and a piece of apparatus for simply and quickly measuring soil resistivity is described.

\section{CONTENTS}

I. Introduction

iI. Previous investigations

1II. Scope of recent investigations

IV. Organization and method of making tests.

V. Currents found to be of galvanic origin and related to soil resistivity -

VI. Character of galvanic circuits involved in pipe-line currents......

VII. Presentation and discussion of data

VIII. Relation of long line currents to corrosion

IX. Relation of electrical resistivity of earth to corrosion

X. Stray currents

XI. Practical significance of data and technique of making measurements

1. Method of measuring line currents......

2. Method of measuring soil resistivity

XiI. Summary

\section{INTRODUCTION}

The present tendency in the protection of pipe lines against soil corrosion is away from a uniform coating, such as has been applied frequently in the past without regard to soil conditions, and toward 
the application of protective coatings which are selected with regard to the corrosiveness of the soil involved. Experience has shown that the deterioration of rolled pipe in many types of soils is so slight as to make it uneconomical to use protective coatings. Other soils are so destructive to pipe materials as to call for the use of the best protective materials and processes available. Intermediate conditions also exist.

Sharp differences in corrosive properties occur from place to place in any one type of soil as well as between types and the problem of detecting such differences becomes a very pertinent and practical one in connection with the coating policy for new lines and the reconditioning of old lines. Several pipe line companies have reported that the proportion of their piping systems subjected to unusually severe soil conditions and, therefore, calling for special protective treatment is very small. Local areas of exceptionally corrosive soil, commonly termed "hot spots," are prevalent over a large proportion of the area traversed by piping systems. Some of these hot spots are of artificial origin, such as salt washes from oil wells, disposal products from manufacturing or refining plants, cinder dumps, etc. However, a great many of the unusually corrosive spots appear to be naturally occurring areas of high salt concentration. $\Lambda$ s such areas usually can not be identified from surface conditions or even by a visual inspection of the soil, their location by other means becomes a matter of importance. This paper describes a method for locating and outlining the limits of cxcessively corrosive soil areas along existing pipe lines. It contrins a review of the work begun several years ago by K. H. Logan, and a more detailed account of the investigations of the author during the spring and summer of 1930 .

\section{PREVIOUS INVESTIGATIONS}

In 1929 Logan, Putnam, and Rogers published a paper ${ }^{1}$ in which they gave the results of measurements of electric currents on oil lines in widely separated sections of the country. As prior to that time the presence of electric currents on pipe lines had usually been attributed to electric railways, the prper was of unusual interest as it showed that such currents could originate from other causes. Although they suggested several possible sources, such as galvanic potentials, condensation of fog on tanks, pumping operations, and magnetic storms, their data seem to justify the conclusion that galvanic potentials were definitely responsible for at least some of the observed currents. More recently Gill and Rogers, who collaborated with Logan on the collection of his data, have extended their tests and presented their findings in a report ${ }^{2}$ in which they definitely at tribute the observed currents to galvanic action.

While Gill found no striking correlation between corrosion and areas of current discharge on pipe lines, at least two of the lines explored by Logan indicated such a relation. Logan found little if any relation between electrical current flow and water courses; both investigators usually found relatively large currents entering tank farms and pumping stations; also, both found currents circulat1 K. II. Ingen, Wulter Rogors, J. F. Putuam, Pipo Line Currents, Am. Pet. Inst., D. å P. E. Bull.
No. 204, p. Ilp.

5, 1830 . 
ing between old and new pipe lines, the latter being the corroding element. Gill found erratic variations in current flow following heavy rains. Neither investigator reported any measurements of earth resistivity in connection with his studies.

Figure 1 shows the results of current flow measurements made by Logan and Putnam on a line of the Standard Oil Co. of California, and later correlated with the corrosion record of the line. To understand the diagram, it is necessary to keep in mind the direction of the flow and the change in magnitude of the current. Thus, the first cross-hatched area lies below a section of pipe along which the current flowed toward the south and decreased in magnitude along the line from north to south. This means that the pipe discharged current along the cross-hatched section. The solid section from $A$ to $B$ indi-

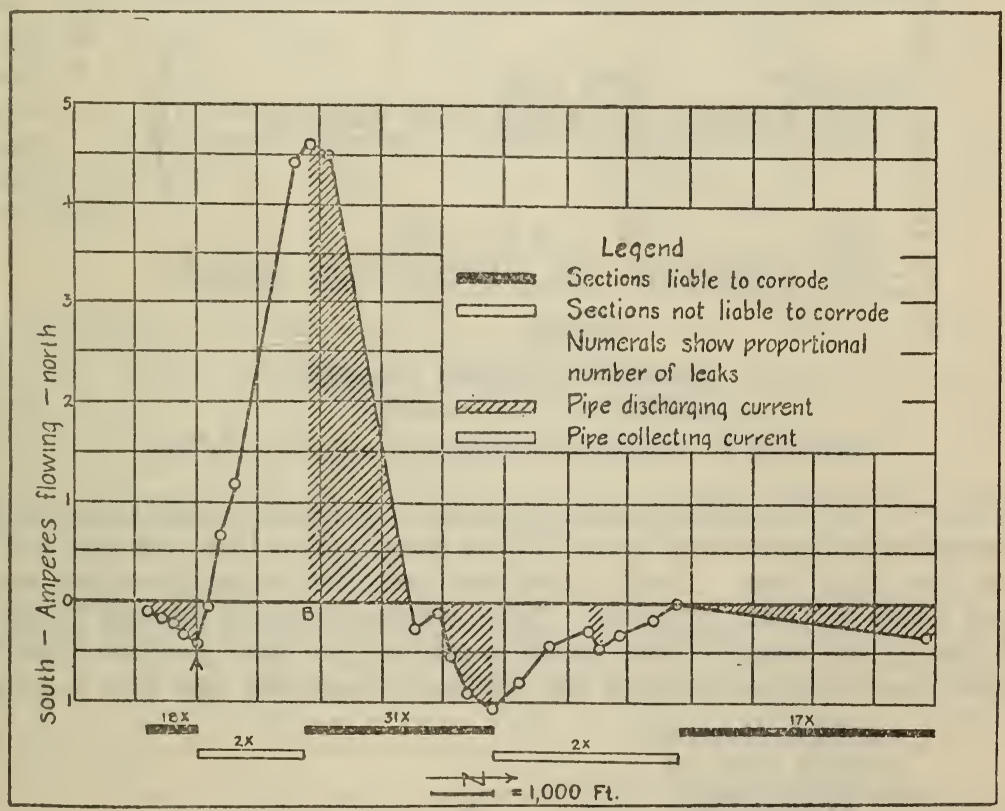

Figure 1.-Association of current discharge and leaks

cates that, starting at $A$ and traveling northward, we find a decreasing current, a reversal, and then an increase in current which reaches a maximum at the point $B$. Between $A$ and $B$ the pipe is collecting current. The remainder of the diagram is interpreted similarly. The graphs below the line show the corrosion as indicated by the record of leaks. The relation to discharge of current is unmistakable. Included in the studies of Logan and his associates was 30 miles of a line of the Marland Oil Co. in Oklahoma, in a territory more than 30 miles distant from the nearest electric railway. Measurements in detail on several thousand feet of this line are shown in Figure 2. The frequent changes in direction or magnitude of the current at different points along the line and the gradual change in the magnitude of the current from pipe section to pipe section are clearly indicative of galvanic origin. It will be noted that between the point $A$ and 
section $E F$, there is a loss of current of 0.97 ampere in a distance of about 1,200 feet. Of this, 0.41 ampere occurs on the first section of about 100 feet, 0.27 ampere entering the section from the south and 0.14 ampere from the north. It is significant that subsequent inspection showed this section to be corroded and other portions of the line to be comparatively good.

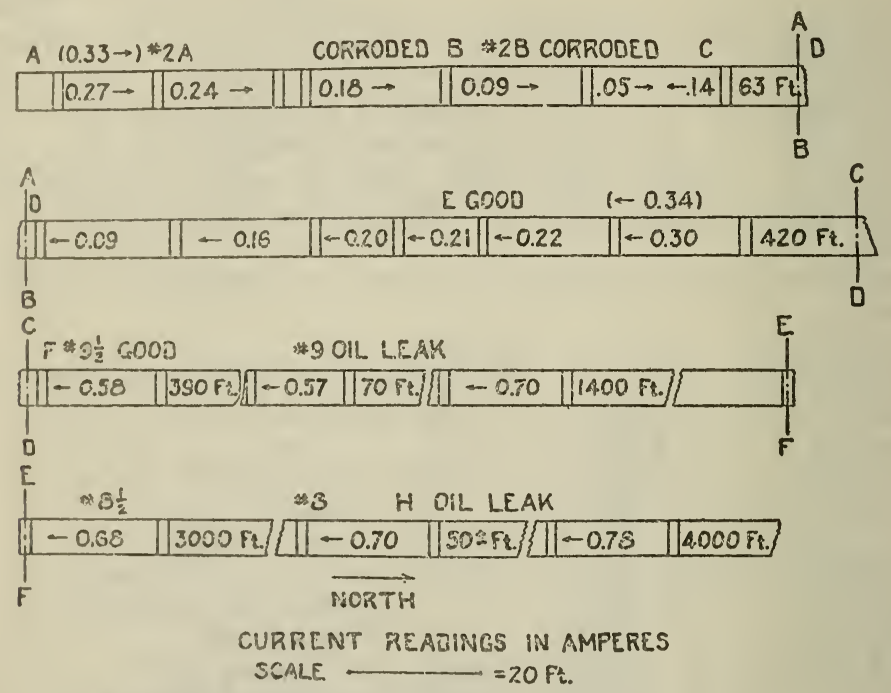

Figure 2.-Deiails of current on 2 milcs of pipe line

Figure 3 is an exccllent example given by Logan of galvanic action between an old and new line. The wrought-iron line was laid earlier than the steel line. Both lines run parallel to each other about (i feet apart through a marsh. Since we find current flowing from the old live to the new via the metallic circuit, we may assume that the circuit is completed through the earth, or that the new line is anodic

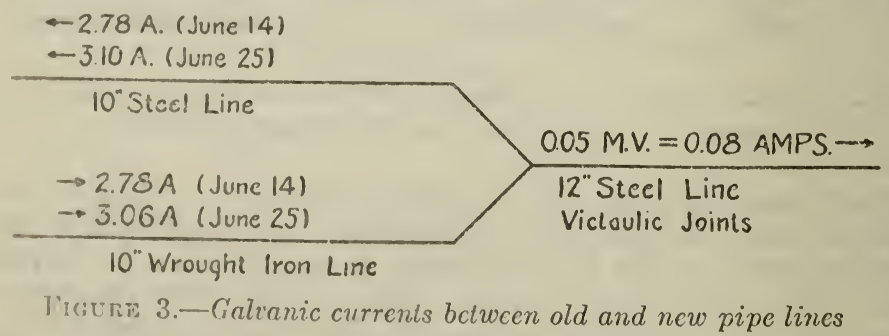

with respect to the old one. This is in accord with the of ten expressed theory that corrosion products tend to accelerate corrosion on exposed connecterl metal structures. It may explain why, in some instances, the original line in a pipe system outlasts those laid subsequently.

\section{SCOPE OF RECENT INVESTIGATIONS}

Since the work of Logan and others indicated that measurable clectric currents, probably of galvanic origin, are to be found on practically all pipe lines, it was deemed worth while to extend the 
scope of these investigations under conditions which would permit of examining the pipes for corrosion, to see if any relation exists between such corrosion and line currents. The more recent investigation extended over a period of nearly three months beginuing April 1, 1930, and was made on nine pipe lines totaling approximately 60 miles of explored pipe. These ranged in location from the gulf coast through Texas and Oklahoma to southern Kansas.

The National Bureau of Standards solicited cooperation in this work from the pipe-line companies through the American Petroleum Institute. The response was so generous that only a fraction of the offers for assistance could be taken advantage of. In selecting a few pipe lines for examination from among thelarge number that were av ailable, consideration was given to a number of factors, chief of which were: (1) Conditions for examining corrosion or availability and accuracy of leak record; (2) kind, age, and condition of protective coating; (3) isolation from other lines and from electric railway disturbances; (4) accessibility with respect to working and living conditions. Selections were made with the idea of covering as wide a variety of soils as possible with the minimum of time and travel. Portions of the following lines were explored in the order given:

\section{Lines tested}

Line E.-Empire Pipe Line Co.; 8-inch oil line neэr Perry, Okla.; 10 to 15 years old, bare, being reconditioned while in service.

Line ST.-Sinclair Pipe Line Co.; 8-inch oil line from Burbank to Tonkawa, Okla.; 7 years old, coated with asphalt, being reclaimed.

Line SB.-Sinclair Pipe Line Co.; 6 and 8-inch oil line from Tonkawa to Billings, Okla.; 5 years old, being reclaimed.

Line SK. - Sinclair Pipe Line Co.; 6-inch oil line from Jonesberg to Coffeyville, Kans.; 8 years old, bare, being reconditioned in spots.

Line G.-Gulf Pipe Line Co.; 6-inch oil line from Crosby to Lynchberg, Tex.; 15 years old, bare, some leak data available.

Line P.-Pure Oil Pipe Line Co. of Texas; 8-inch oil line through Spindle Top Gulley, near Beaumont, Tex.; in area known to be highly corrosive.

Line HB.-Humble Pipe Line Co.; 8-inch oil line from Beaumont to Hull, Tex.; 4 years old, thin bituminous coating. No leals have occurred on this line.

Line HH.-Humble Pipe Line Co.; 12-inch oil line from Hearne to Groesbeck. Tex.; 7 years old, light bituminous coating. No corrosion leaks have occurred on this line.

Line HV.-Humble Pipe Line Co.; 6-inch oil line from Vernon to Swastika, Tex.; 7 years old, light bituminous coating. Recent inspection record and leak record available.

\section{ORGANIZATION AND METHOD OF MAKING TESTS}

Assistance rendered by the pipe-line companies consisted of an engineer with his car and one or more helper's, some member of the party being familiar with the location of the line and the roads leading to it. Measurements of current flow on the line were made by observing the potential drop on a 75-foot length of pipe with a very sensitive millivoltmeter. Contacts were made on the line by prodding down to the pipe with a steel bar, then inserting diamond point drill rods in the holes and twisting or tapping these until they made good contact with the pipe. Where reconditioning work was in progress or where pipe was being salvaged measurements were sometimes made after the top of the pipe had been exposed. This was possible at times on lines E, ST, and SB. Where such work was in progress 
the procedure was to explore the line for current several miles in advance of the operations and then to inspect the pipe for corrosion after it was taken out of the ground. In the first three lines examined the work of uncovering the top of the pipe was pushed several miles ahead of any other operation, thus permitting access to the surface of the pipe before electrical conditions on the line were greatly disturbed. Measurements of the electrical resistivity of the soil were made in the field by a direct-current method, the details of which are described later.

\section{CURRENTS FOUND TO BE OF GALVANIC ORIGIN AND RELATED TO SOIL RESISTIVITY}

It was evident soon after starting the work that the currents observed on line E were largely of galvanic origin. Small variations at any one point were attributed to distant interurban electric lines, but abrupt changes in magnitude from point to point along the line indicated that the currents originated at the pipe surface. Currents were found to be flowing into certain sections of the pipe line from both directions and away from other sections in both directions. Moreover, these currents remained substantially constant day after day, except for the small stray fluctuations referred to. A more detailed study showed that as a rule the current accumulated on the pipe gradually over a considerable length and discharged abruptly over relatively short sections of the pipe line.

A study of the soil along the line, including electrical resistivity measurements, showed that invariably the areas of abrupt discharge were in soils of low resistivity, while the areas of collection or little change were in soils of normal or high resistivity. When the pipe came out of the ground and was cleaned, additional measurements of soil resistivity were made and these revealed a striking relation to the observed corrosion, the pitting and rusting being most severe in soil areas of unusually low resistivity. Here, then, was a three-way correlation between line currents, soil conductivity, and corrosion. As the work progressed to other lines these relations were found to hold truo quite generally; in some instances the correlation was striking, while in other's it was less definite.

\section{CHARACTER OF GALVANIC CIRCUITS INVOLVED IN PIPE LINE CURRENTS}

Before discussing the data in detail we will describe the manner in which galvanic currents are built up to produce measurable currents on pipe lines and in so doing will adhere to the generally accepted electrochemical theory of corrosion.

Among the possible sources of electromotive force by which galvanic currents on pipe lines are generated we may list the following static potential differences:

1. Potential differences between bright iron and mill scale.

2. Potential differences between different points on the pipe due to strains, inequalities, impurities, ete. Usually of the order of
millivolts.

3. Potential differences between difierent kinds of pipe or between new and old pipe. 
4. Potential differences resulting from soil differences. These may be local in character, such as occur in irregular or nonhomogeneous earth, or more extensive, such as between different kinds of soils. All degrees of soil difierences are possible, ranging from minute irregularities to major differences in extensive soil areas. In this group must also be included differences in moisture content, also differences in oxygen and in salt concentrations.

Many of the galvanic potentials listed above are local in their action. Abrasions, strains, discontinuity of mill scale, impurities, and similar conditions tend to establish galvanic currents which are local in character and usually affect a relatively small portion of the pipe surface. lilkewise the action resulting from concentration cells is local, but may be more frequent in occurrence. Figure 4 is intended to illustrate local action where a relatively small fraction of the pipe area is undergoing corrosion. The

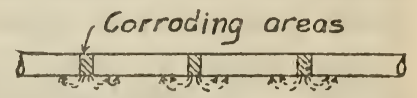

Figure 4.-Galvanic currents on pipe, in which the affecterl area is relatively small and. in which no long line currents are produced

- electric circuits are small in extent because of the plentiful supply of cathodic pipe surface adjacent to the corroding areas. As the anodic area becomes larger the current in the earth increases and appreciable amounts of current are found at points more remote from the anode. This condition, illustrated in Figure 5, will produce measurable currents on the pipe line, or "long line" currents. The extent of such circuits depends upon the length of pipe so affected and the proportion of pipe within the affected area which is actually undergoing corrosion, or in other words, from which current is being discharged.

In Figure 6 the entire surface of the pipe within a corrosive area or "hot spot" is shown to be discharging current. This may not actually occur in practice, but the proportion of the pipe area undergoing corrosion, and, therefore, from which current is leaving, is often very great in such soil areas. This current returns in sweeping streamlines through the earth to the pipe, the density diminishing with in-

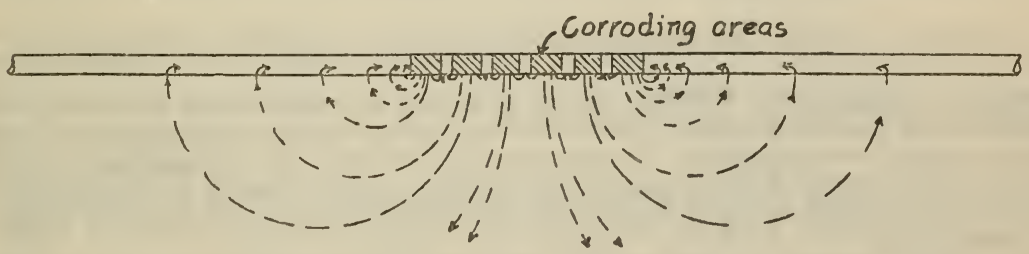

IIGURE 5.-Galvanic currents on pipe, in which the affecled area is relatively large and in which long line currents are produccd

creasing distance from the point of origin. The magnitude of the current on the pipe at any point is shown by the current curve. A current flow from east to west is plotted above the base line, while a flow from west to east is plotted below the base line. It will be seen that on approaching the corrosive area from either direction the magnitude of the pipe-line current increases and that throughout the corrosive area the current is decreasing. An ascending slope in the current curve from left to right represents a discharge of current from the pipe, while a descending slope from left to right represents a 
collection of current. This is true both above and below the base line. It is, of course, also understood that a discharge of current from a pipe is usually accompanied by corrosion while a collection of curren $\iota$ is not.

\section{PRESENTATION AND DISCUSSION OF DATA}

Line E.-The soil and topography in Noble County, Okla., through which line E extends, is so similar to that in Payne County, for which a report of the United States Bureau of Soils is available, that we will quote that report as applicable to the case at hand:

Payne County lies within the great plains province, as defined by the Bureau of Soils. The upland soils are derived principally from rocks of the Permian and Pennsylvania divisions of the Carboniferous. * * * The soils residual from the Permian Red Bed prevailingly partake of the color of the parent rocks and are classified in the Vernon Series. The other important soil series, the

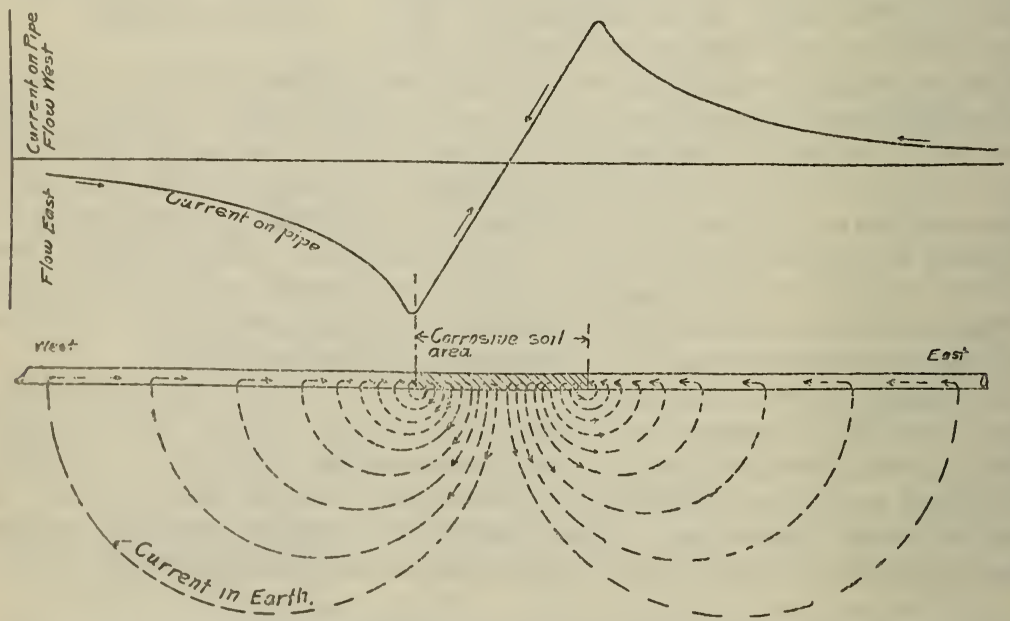

FIGURE 6.-Effect of localized corrosire soil areas on production of line currents

Firkland, coming from Permian rocks, is brown in color rather than red. Its difference in color is probably due to the long period of time during which it has licen subject to weathering. In the areas of red soils the topography is more rolling, the bedrock is mich nearer the surface and the soil is more subject to crosion than in the areas of brown soil, where the topography is gently sloping or nearly level. * **

In texture the residual upland soils range from fine sandy loams to clay, with loam and fine and very fine sandy loams predominating. The subsoils are charactcristically much heavier than the soils. The latter are generally mellow and friable, while the subsoils range from stiff and plastic to moderately friable, and even when friable are usually compact.

A survey of galvanic long-line currents was made over approximatnly 9 miles of this line. Five reversals were discovered. The maximum current observed was 1.5 amperes. Figure 7 shows the current flow on the line and the earth resistivity along a typical $1 \$, 000$-foot section. The current flow is plotted in accordance with the nxplanation of Figure 6. It will be seen that two reversals occur in tivis section. Eurth resistirity in ohm-centimeters is plotted as 
ordinates from the base line. Values greater than 7,000 ohm-centimeters are not shown, but are roughly indicated by the slope of the resistivity curve.

The resistivity of the soil along this line varies sharply nver a wide range. For the sandy loams which predominate it is from 3,000 to 12,000 ohm-centimeters. Many irregular outcrops and pockets of red coarse clay and of yellowish and whitish clays occur, and these range in resistivity from 2,000 to less than 400 ohm-centimeters. Black bottom loams and clays range around 1,000 ohm-centimeters and sometimes lower. In some sections the soil is quite deep and uniform, and where this condition is found the pipe showed little if any evidence of corrosion. In other regions where the soil is bioken by outcrops of heavy red coarse clay, alkali soil, and other types of irregular soils, the location of the corroded sections of the pipe coincided in a striking manner with the irregular and low resistance soils. These bad areas were not always in low ground, but often occurred

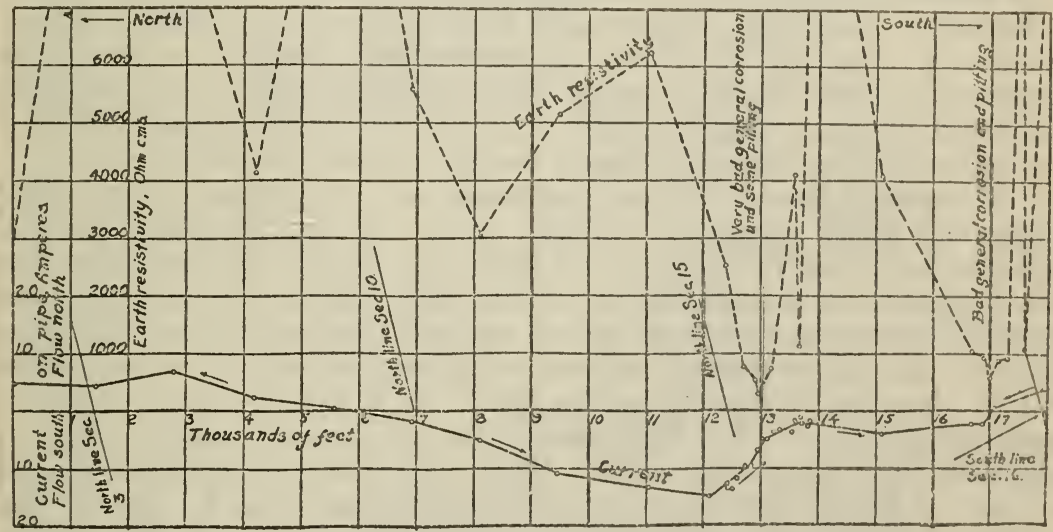

Figure 7.-Line E; electric currents and soil resistivily along 8-inch oil line, Noble County, Oisla.

on the slopes and higher elevations. Soils of the Permian group are likely to contain alkali salts, and it is probably the presence of such salts in relatively high concentrations that produces the low resistivities encountered.

In Figure 7 will be seen two zones, one at 13,000 and the other at 17,000 feet, in which abrupt discharge of current takes place, and both of these coincide with areas of unusually low soil resistivity. An inspection of the pipe when it was uncovered and placed on skids for reconditioning showed a heavy encrustation of rust for several hundred feet in the vicinity of station 13,000. Some pitting was also in evidence, but it was not acute. At station 17,000, for a distance of about 75 feet, the pipe was deeply pitted. The presence of two leak clamps indicated that failures had previously occurred. The shape of the current curve between 6,000 and 13,000 feet bears a strong likeness to the corresponding portion of the theoretical curve shown in Figure 6. It is quite evident that the current discharging from the pipe between 12,000 and 14,000 feet is returning to the line between 6,000 and 21,000 feet. Some of the current curves in Figures $8,11,12$, and 14 , show an even more striking resemblance to the 
theoretical curve. The variable character of the soil is indicated in the following table which shows conditions at station 17,000 in greater detail than are given in Figure 7.

TABLE 1.-Variations in soil resistivity, line $E$

\begin{tabular}{|r|r|l|}
\hline Station & Resistivity & Condition of pipe \\
\cline { 2 - 3 } 16700 & $\begin{array}{r}\text { Orm-cm } \\
1,071\end{array}$ & Fair. \\
16850 & 966 & Do. \\
16925 & 2,016 & Do. \\
17000 & 546 & Very bad (leak clamp). \\
17010 & 370 & Do. \\
17100 & 966 & Bad. \\
17200 & 891 & Do. \\
17250 & 658 & Very bad. \\
17350 & 1,176 & Bad. \\
17800 & 9,300 & Good. \\
\hline
\end{tabular}

In addition to the fairly extensive areas of low soil resistivity shown in Figure 7, there are innumerable small outcrops or pockets, sometimes only a few feet in extent. In such places the amount of current discharging from the pipe was too small to be detected by the methods employed in measuring long-line currents, but their corrosive nature was quite evident when the pipe was exposed and cleaned.

The curve in Figure 7 is not presented as a complete picture of the changes in earth resistivity in that area. At the time this line was explored no rapid method of making earth resistivity measurements was available, consequently such tests were made only at infrequent intervals except at points of abrupt current discharge where the character of the soil appeared to have some relation to the current fiow and to observed corrosion on the pipe. It is probable that at intermediate points in the high-resistance soils many small areas of relatively low resistivity exist. This was found to be true on other sections of line $\mathrm{E}$ that were being reconditioned prior to starting the current survey, and, therefore, on sections where no current flow data were obtained, but on which a careful comparison was made between corrosion and earth resistivity. In some of these sections corrosion was most erratic, being severe for a few feet or on one or two joints of pipe, and entirely absent on others. It was in such regions that the numerous and erratic areas of low-resistance soil occurred, and these coincided with the badly corroded sections of the pipe line.

There was a general belief among those associated with the repair of the pipe line that oil leaks were responsible for much if not most of the corrosion, and a casual inspection of the line would certainly lead one to this opinion. However, a careful examination of the soil and measurements of its resistivity showed that most of the barren spots where grass did not grow were of a different soil, having a low resistivity, and were not the result of oil leaks. This fact was demonstrated repeatedly, both along the line and at some distance from it. There is sometimes the question of which came first, the leak or the corrosion. Where a leak clamp is found it may be assumed that a bad soil condition caused the failure and is responsible for any otner corrosion in that vicinity. But where a collar leak is found, accompanied by corrosion on the downhill side only, the evidence is rather convincing for the oil theory. It is not the intent in this discussion to overthrow this theory of corrosion as it seems to be a universally accepted one. It 
does appear, however, that at times it may be greatly orerworked. Such an effect, if confirmed, might be caused by local differences in oxygen concentration brought about by the presence of oil.

Line ST.-The soil through which this line extended is of a much more uniform and homogeneous character than that on line E, 30 miles to the south. This condition and the presence of a bituminous coating in a fair state of preservation probably account for the relatively small currents that were found on the line, the maximum values of which were about 0.5 ampere. Although several current reversals were observed, there was only one point where the current discharge was of sufficient magnitude and density to indicate the possibility of corrosion. This was on a rocky hillside at a point where a senp or swampy outcrop existed and where a loss of 0.2 ampere occurred in a distance of 100 feet. The soil resistivity was about $1,800 \mathrm{ohm}$ $\mathrm{cm}$. The pipe was examined upon removal and found to have failed

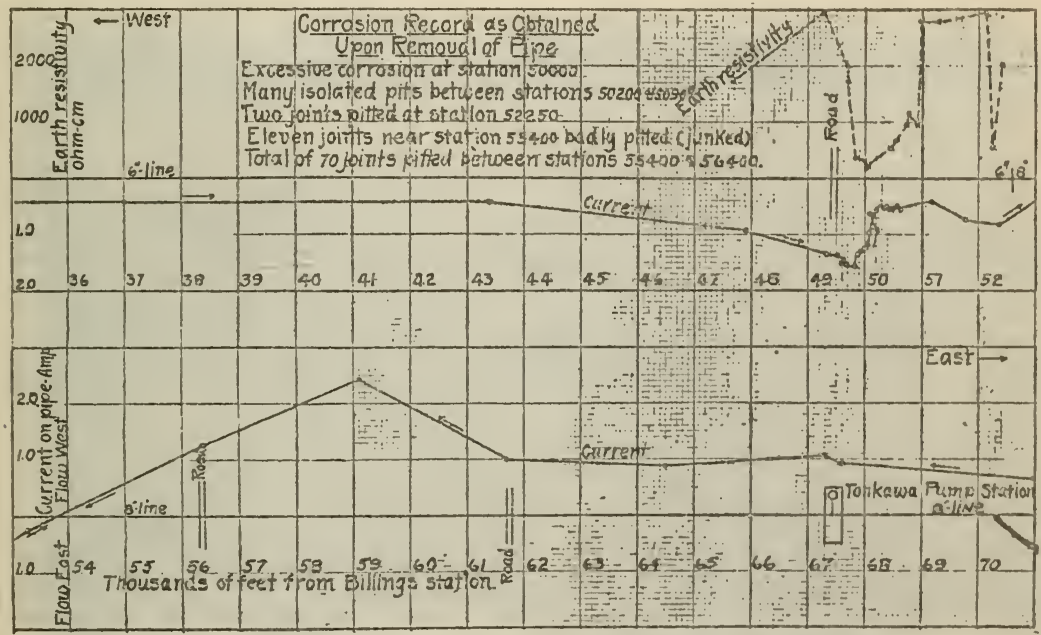

FIGURe 8.-Line SB; electric currents and soil resistivity along 6 and 8 inch oil line, Noble and Kay Counties, Okla.

completely at one point. Many pits from 0.2 to 0.3 inch deep were observed. The pits were very sharp and regular and filled with 2 yellow product of corrosion at the top, and with black oxide in the bottom. Although acute at points, corrosion had occurred on only a small fraction of the pipe surface.

In this case the soil resistivity did not tie in so well as in others where bad corrosion has been found. In fact, it is the only case involved in this investigation where severe corrosion was observed in soil other than that of unusually low resistivity. Generally, the soil in the hilly region where this springy outcrop occurred has a resistivity of from 5,000 to $12,000 \mathrm{ohm}-\mathrm{cm}$. At the point in question the values were from 1,500 to $2,000 \mathrm{ohm}$-cm, or considerably lower than soils immediately adjacent. Perhaps relative resistivity rather than the absolute value is an important factor in the corrosion problem in some soils.

Line $S B$.-Figure 8 shows the long-line galvanic currents on about 7 miles of this line, part of which lies within the area of the Three- 
Sands oil field. The field extends roughly from the road at 49,400 to the road at 61,700 . Salt water from the wells has overflowed portions of this field and is probably responsible for the severely corrosive conditions observed.

The most abrupt discharge of current observed throughout the investigation occurred in the vicinity of station 50000 , and this was accompanied by a drop in soil resistivity from the normal values in this region of about $3,000 \mathrm{ohm}-\mathrm{cm}$ to less than $200 \mathrm{ohm}-\mathrm{cm}$. The pipe at this location was practically destroyed as shown in Figure 9. The extent of damage at other points, as reported by the company engineers, is indicated in Figure 8.

Because of the condition of the ground at the time of test and the difficulty of locating the line through the oil field, only a few readings were made between stations 53000 and 62000 . It is unfortunate that no data on soil resistivity are available in this territory. At the timo

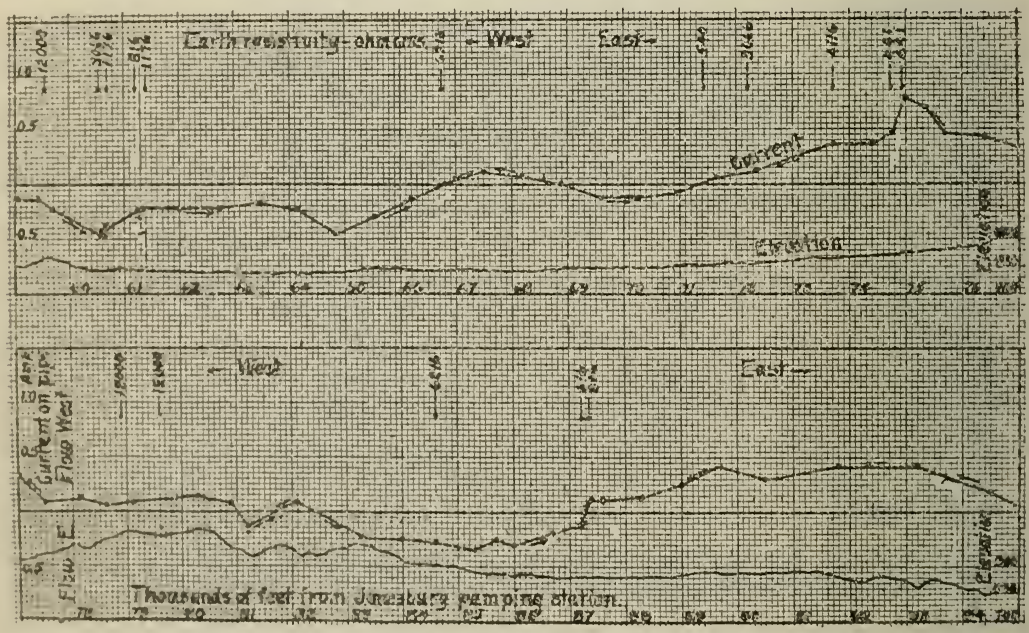

Figure 10.-Line SK; electric currents and soil resistivity along 6-inch oil line, Jonesburg to Coffeyville, Kans.

the measurements were made it was supposed that the line made contact with other pipes in the oil field and that the large loss in current was due to current interchange at such points. However, the engineers who were on the ground at the time the pipe was removed reported that no such contacts existed. As salt water has been discharged from the wells in this oil field at different locations from time to time, it is not probable that the line currents and soil resistivities here recorded have always prevailed during the life of the pipe. It is not reasonable, therefore, to expect too close a correlation between the observed corrosion and present electrical conditions.

line SK.-This line runs through a rather flat region in which farm and grazing lands predominate. Low ranges of hills at intervals of several miles occur as shown by the profile in Figure 10. For the most part the soil is a black, or brown silty loam. The subsoil is often yellowish or gray clay.

Fignure 10 shows the results of a current-flow survey over a 7-mile siretch of the line. The soil resistivity at a few points is given in 
B. S. Journal of Research, RP298

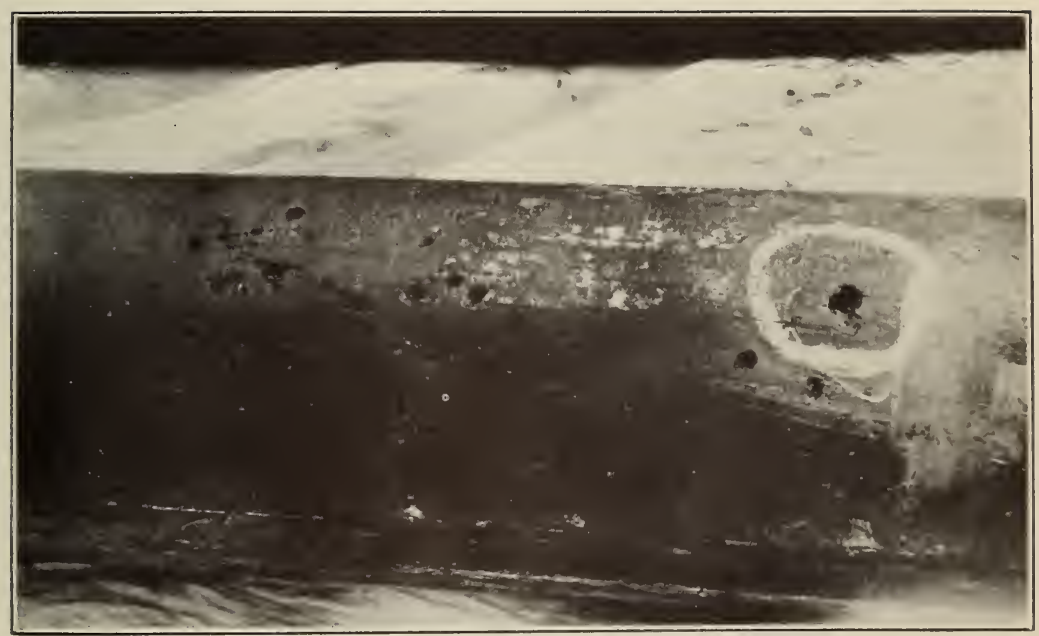

FIgUre 9.-Pipe removed from line SB, at station 50000 
figures. Six reversals of current were observed and three points of concentrated discharge. At the time the tests were made, the pipe was exposed for reconditioning at station 60600 and was found to be badly corroded. It will be seen that a rather sharp discharge of current takes place at this point and onto 61300 . The earth resistivitity is also relatively low, being around $1,000 \mathrm{ohm}-\mathrm{cm}$, whercas the normal values of resistivity range from 3,000 to $12,000 \mathrm{ohm}-\mathrm{cm}$. Two other points of abrupt discharge occur at stations 74900 and at 87300. It will be seen that both of these are associated with abnormally low earth resistivity. These two locations were cited for inspection and repair, and later the following report was reccived from one of the engineers of the pipe-line company:

Our line in Kansas has a heavy red rust with some pitting. Your discovery of loss of current at the points where you recommended reconditioning saved this pipe because in a short time it would probably have corrocied out.

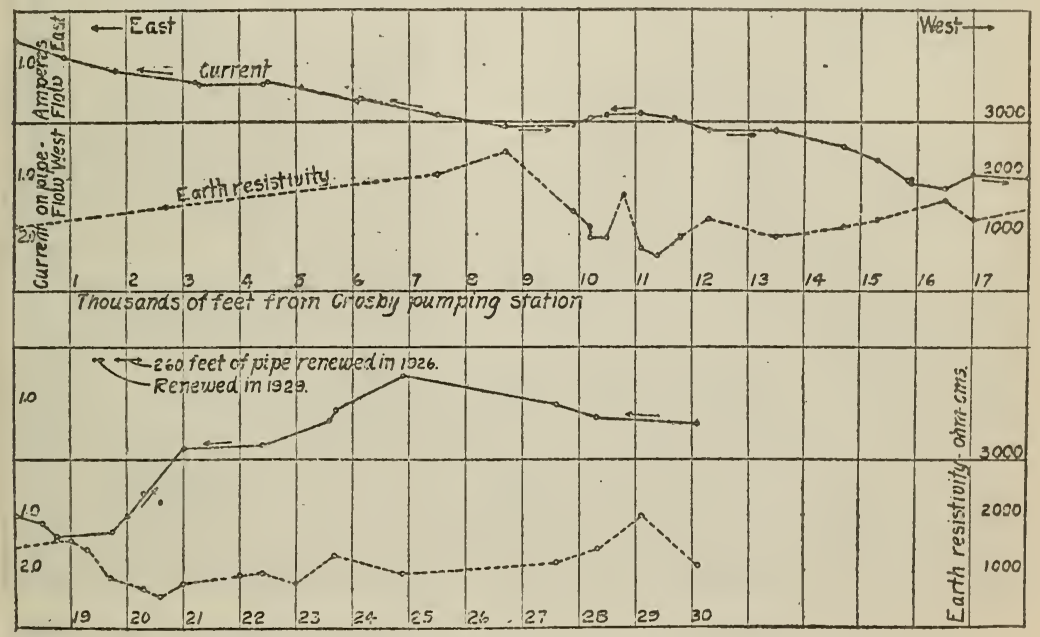

FIGURe 11.-Line G; clectric currents and soil resistivity along 6-inch oil line Harris County, Tex.

The interesting and significant thing about this line as well as most of the other lines explored, is the exratic changes in soil resistivity in regions where surface conditions appear to be uniform.

Line G.-This line lies in the coastal plain at an elevation of about 45 feet above sea level. The topography and vegetation appear to be uniform throughout the 6-mile stretch explored. The top soil is black loam and the subsoil varies from a bluish gray clay shot with red, to a light yellow clay shot with red. Even under the apparently uniform conditions prevailing along this line the earth resistivity was found to vary from about 600 to $2,500 \mathrm{ohm}-\mathrm{cm}$.

The results of current fow and resistivity measurements are given in Figure 11. The cast end of the line for a distance of about 2 miles is collecting current and delivering it to the Crosby pumping station. and tank farm, the current entering the station being about 1.5) amperes.

Two low points in the resistivity curve exist, but only one is accompanied by a heavy discharge of current. A loss of 1.5 amperes occurs 
between stations 19750 and 21000 , and this area includes the lowest soil resistivities encountered. In 1926 a stretch of several hundred feet of pipe was replaced in this section. The small section renewed in 1929 may also fall within the area of heavy discharge, but as no measurements were made between 18750 and 19750, the shape of the current curve between those points is not definitely known. No other renewals than those shown have been made on this portion of the line, but leak clamps have been installed at a few points.

Line P.-Spindle Top Gulley is well known by the pipe line companies as a region of extremely corrosive soil. The measurements recorded in Figure 12 were made along an 8-inch line which runs

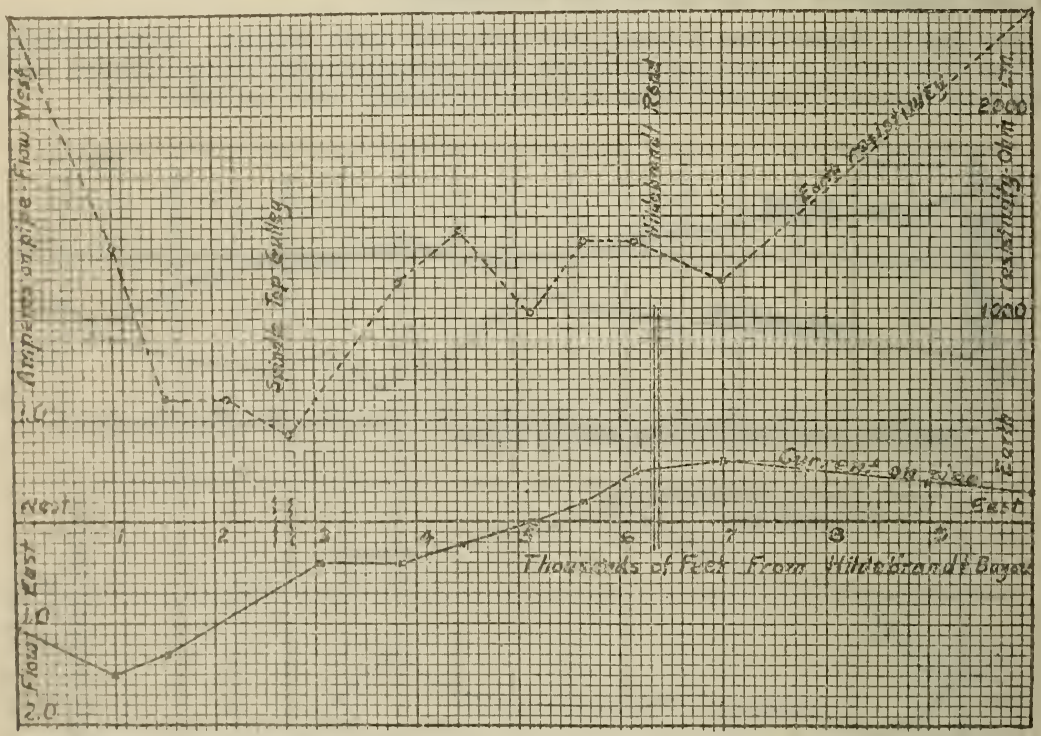

Figure 12.-Line $P$; electric currents and soil resistivity along 8-inch oil line through Spindle Top Gulley

through that territory. Engineers of the company state that the worst corrosion has occurred between stations 2000 and 3000 as shown in Figure 12. It will be seen that this is also the region of highest current discharge and lowest soil resistivity. The correlation between current discharge, soil resistivity, and corrosion is therefore strikiner.

In this case, however, there appears to be a better correlation betwecn soil resistivity and corrosion than between current discharge and corrosion. Loss of current occurs at a fairly uniform density over several thousand feet of pipe, but replacements have been made only in the region of unusually low resistivity.

Line MB. -This line lies in the low lands of the coastal plain and runs through rice fields, open pasture land, and pine and oak woods. 'The soil is a heary black rlay loam for the most part, underlaid with yollow or gray mottled clay. Pockets of silty clay occur at some points and hervy muck is encountered in a few locations. The water table was found to be near the surface in some of the pasture lands, although the top soil was very dry. The soil resistivity was com- 
paratively uniform, ranging from about, 1,000 to $3,000 \mathrm{ohm} \mathrm{cm.,}$ except in a few locations where silty soils of a much higher resistivity were encountered. Relatively small currents were found on this line and no points at which concentrated discharge took place. The greatest loss in current occurred in flooded rice fields where it was impracticable to trace the discharge in detail. As the measurements on this line reveal no line currents of appreciable magnitude and no areas of low resistivity they confirm in a general way the good record of no corrosion trouble whatsoever during the 4-year life of the line.

Line HH.-Figure 13 shows the results of measurements on line $\mathrm{HH}$, which runs through a rolling country of scrub oak woods and. farm lands, the elevation being 400 to 500 feet above sea level. The soil on the uplands is largely yellow sand having a very high electrical resistivity. In the lower and farm lands the silty and sandy top soils are underlain with a heary yellow clay having a relatively low resistivity. The depth to this subsoil is quite variable. Outcrops of it occur in many places, but for the most part it is below pipe depth. Erratic soil resistances at pipe depth are due to variations in the depth of this clay below the ground surface.

A very satisfactory correlation between current discharge and earth resistivity is shown in Figure 13. Two points of unusually high current discharge are shown at stations 216000 and 221500, and at both locations the earth resistivity drops to abnormally low values. Both of these points are in corn fields. In the first the corn was yellow and sickly, showing the effect of the clay outcrop. In the other place the corn was green and rank because of sufficient good soil over the clay subsoil. The pipe was uncovered at the edge of the field at station 221500 and found to be pitted to a depth of 0.15 inch. Many pits 0.1 inch deep were found. Because of the growing crop no inspections were made at station 216000.

The regions of low resistivity at station 162000 and 168000 are also accompanied by loss of current from the pipe line, but the density of discharge is relatively small. An inspection of the pipe at station 162000 revealed no extensive corrosion.

The large current of 5.3 amperes on the south end of the line is entering the Hearne tank farm. The collection on the line near the tank farm is very dense as indicated by the steep slope of the curve.

Line HV.-The soil through which this line runs is of a chocolatebrown color and very uniform in appearance. Its resistivity ranges from about 500 to $2,000 \mathrm{ohm}-\mathrm{cm}$. The correlation between current discharge and soil resistivity, as shown in Figure 14, is perhaps more striking than on any of the other lines. At many of the points where loss of current is shown, trouble from corrosion had been experienced. Leaks had been repaired at 157700,159800 , and 204850. New pipe had recently been installed at 193700 and at 201200 .

The heavy loss of current shown at 162500 was probably a temporary condition. One and two days prior to the tests very heavy rains had occurred, following a prolonged drought. This rain had not penetrated to the pipe level except where the trench had heen newly made or backfilled. The location in question is at the site of an old booster station where several months prior to the tests the main had been uncovered for the purpose of removing various connections. No new pipe had been installed, but about 200 feet of trench had $43324^{\circ}-31-12$ 

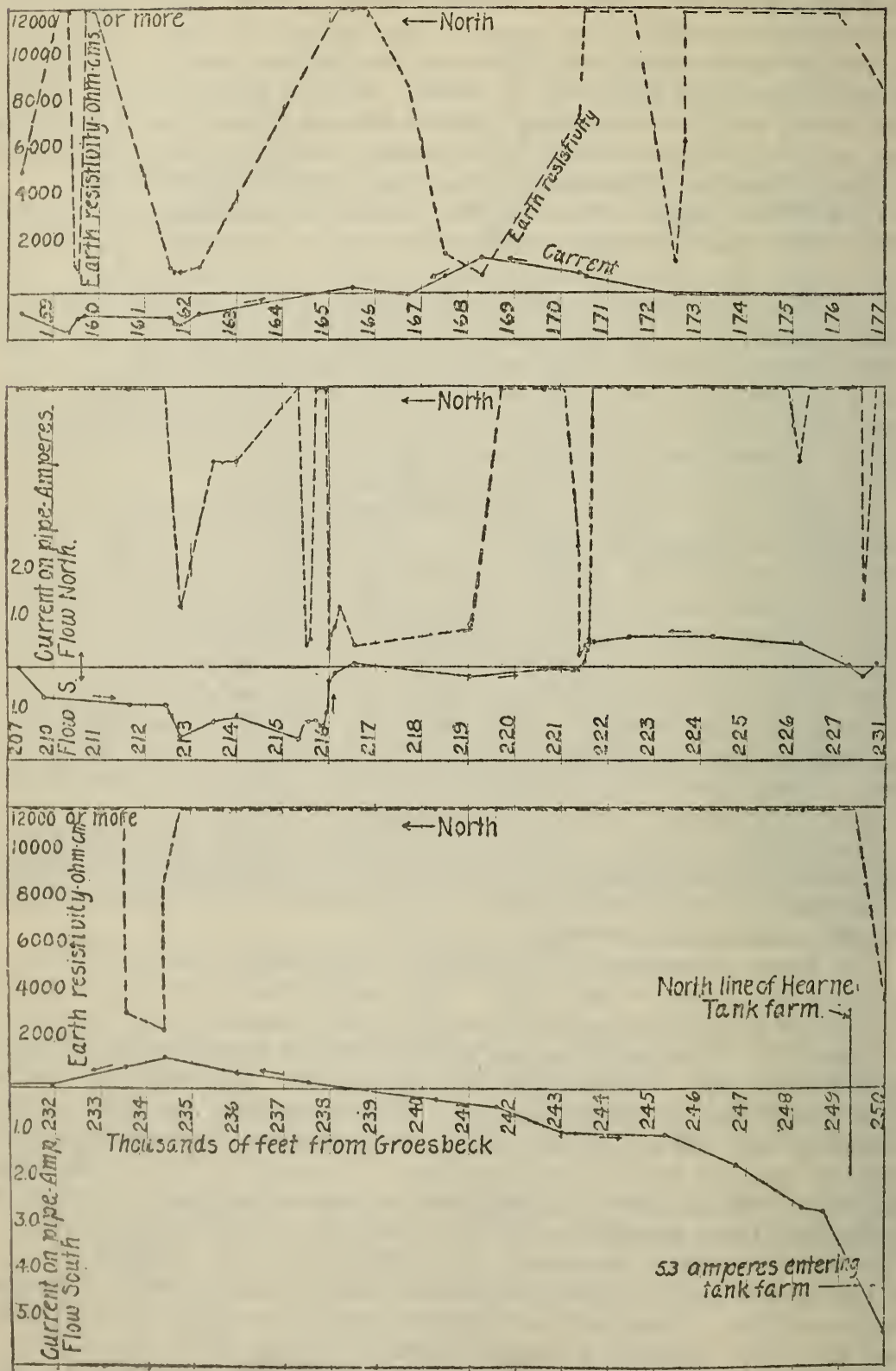

Filutre 13.-Linc IIII; clectric currenls and soil resistivily along 12-inch oil line, Grocsbeck to Hearne, T'ex. 
been opened up and backfilled. The heavy rains had penetrated to the pipe in this area but not in adjacent areas. It seems probable that this condition is in some way responsible for the abrupt loss of current at that point. Similar conditions exist at stations 193700 and 201200. These locations are further complicated by the presence of new pipe. However, at these two locations unusually low-earth resistivities were encountered and as measurements of resistivity were always made outside of the trench area the newly filled trenches can not account for the low values observed.
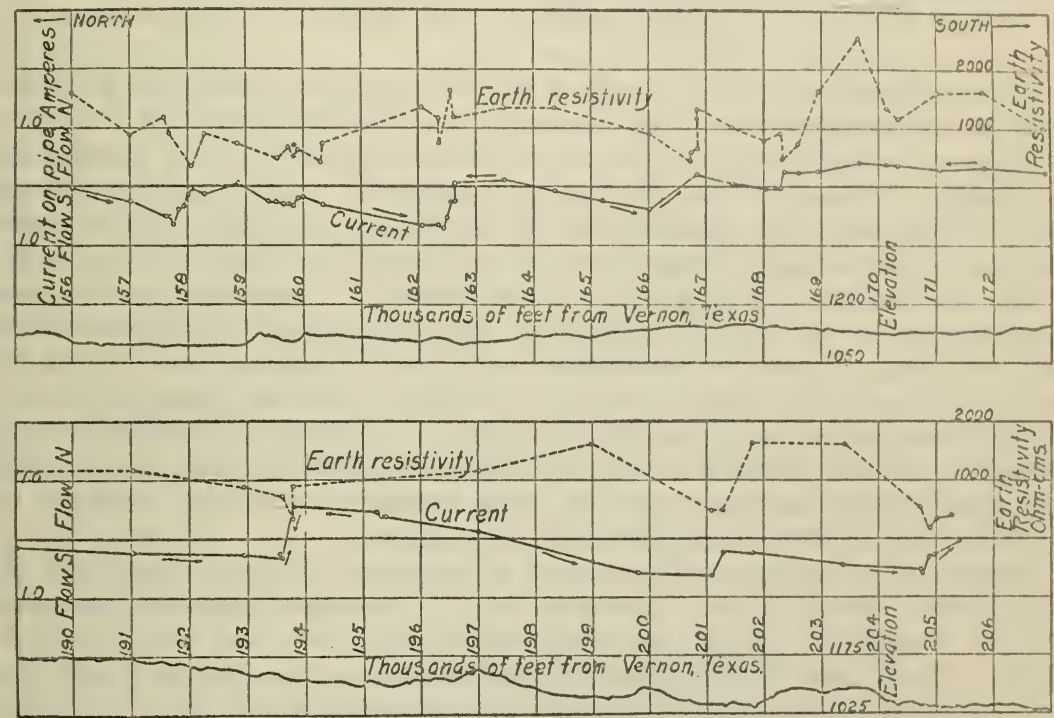

FigURe 14.-Iine HV; electric currents and soil resistivity along 6-inch wil line, Archer County, Tex.

\section{RELATION OF LONG-LINE CURRENTS TO CORROSION}

The correlation between loss of current and corrosion which has been shown to exist on pipe lines, at once raises many questions as to the actual relation between these factor's and the real significance of such currents. It is possible that the long-line currents represent the effects of local galvanic action on the surface of the pipe as shown in Figure 5, or they may be the result of potential differences between pipe surfaces in two widely separated soils. Although potential differences of steel amounting to several tenths of a volt can be obtained in the laboratory between a concentrated alkaline solution and in neutral solution, the potential difference in different soils in any territory is usually less than 0.1 volt. It seems more probable that the currents are the residual results of local action as shown in Figure 5 . The theory is supported by the fact that almost without exception currents are found entering tank farms rather than leaving them. If such currents were generated by differences in soil areas one would not expect to find them always flowing toward the tanks. It appears, therefore, that the currents flowing toward tank farms are the result of a difference of potential between the pipe line and the tank bottoms. 
This may be a difference in metals or a difference in oxygen supply. The latter supposition appears to be the more reasonable.

That currents entering tank farms must have a negligible influence on the corrosion of tank bottoms is shown by the following simple calculation. A tank 117 feet in diameter has an area of approximately 10,700 square feet. At 100 per cent anodic efficiency a current of one ampere will carry into solution 20 pounds of iron in one year, or, when discharging from an area of 1 square foot, will produce a penetration to a depth of about one-half inch per year. Assuming a discharge of 5 amperes from a 117-foot tank, which is a little greater than the maximum discharge rate so far discovered, there would be a penetration of only about 0.000233 inch per year.

As corrosion usually takes the form of irregular pitting rather than of uniform penetration, it is necessary to employ a pitting factor if we are to estimate the pit penetration corresponding to a given loss of weight. Data on the bureau's 8-year-old corrosion specimens show pitting factors ranging from about 2 to more than 40 , the more common values being from 10 to 20 . The pitting factor is the ratio of the maximum to the average penetration. Assuming in this case a pitting factor of 15 , the maximum pit penetration would be 0.0035 inch per year. Such a rate of corrosion would require over 70 years to puncture a $1 / 4$-inch tank bottom. While this calculation is necessarily speculative, it serves to show that line currents should have a negligible effect on the corrosion of tanks and station equipment, and that such corrosion as occurs on tank bottoms must be charged to local, rather than to long-line galvanic action.

Similar calculations with respect to areas of current discharge on pipe lines indicate that a large part of the corrosion in some locations can be accounted for by the action associated with the long line currents. In Figure 13 at station 221500 there is a loss of current of onehalf ampere from a 12-inch line in a distance of 50 feet. This is equivalent to 0.003 ampere per square foot or to an average penetration of 0.0015 inch per year. Assuming again a pitting factor of 15 , we arrive at a yearly penetration of 0.0225 inch or approximately a 10-year life. As this pipe is now seven years old and has not failed, and as the calculated depth of pitting agrees closely with the pitting retually observed, it would seem that the extent of the corrosion occurring at such particularly corrosive spots is roughly indicated by the density of the current leaving the pipe.

This does not mean that unconnected short pieces of pipe placed in these areas would not experience severe corrosion. It simply means that the highly concentrated current discharge from the pitting areas finds an easier return path by way of remote earth and the pipe line, than by short crowded circuits to immediately adjacent cathodic areas, such us would necessarily be the case with short pieces. Such action would probably retard the rate of corrosion somewhat, particularly under conditions where a relatively large proportion of the pipe is rfiected. In soils where the pitting factor is large or when a relatively small proportion of the pipe is affected, it is probs ble that short nipples will show about the same rate of corrosion as tho line itself.

Line currents are, perhaps, more suggestive of the locations of corrosive arens than they are of the degree of the corrosion in any given area. Arute corrosion is not associated with pipe-line currents, except at points of exceptionally dense discharge. Moderate rates of 
discharge such as those shown in Figure 7 do not in thomselves produce excessive corrosion, although they may be associated with and point to acute areas. In Figure 7 the rate of discharge at station 13000 and also at 17000 is approximately 1.8 amperes per thousand feet of 8 -inch line. This is equivalent to 0.00086 ampere per square foot or to an average penetration of 0.00043 inch per year. Issuming again a pitting factor of 15 we arrive at a yearly penetration of 0.0064 inch or approximately a 40-year life. As the pipe line at both of the points under discussion was corroded very much worse than the above figures would indicate, it is evident that the line current as measured represents only a fraction of the action taking place at the points of greatest discharge.

The magnitude of line currents is undoubtedly a function of the extent of the corrosive areas with which they are associated. A local hot spot of only a few feet in extent may cause rapid corrosion and yet not be accompanied by line currents of measureable magnitude. Conversely, corrosive areas of considerable extent will usually be accompanied by relatively large line currents. The magnitude of a line current appears, therefore, to be a better measure of the total amount of corrosion in progress in the discharging zone than it is of the rate of corrosion in that zone. Another factor afiecting the size of line currents, as well as their rate of discharge, is the character of the corrosion with which they are associated. If the corrosion is uniform the current entering a discharging zone will be a better measure of the total corrosion involved than if only a fraction of the pipe surface is affected. An example of this latter condition is to be found on line ST, previously referred to, where acute corrosion in the form of deep isolated pits occurred, but where the loss of current was relatively small. No general quantitative interpretation, therefore, can be placed on either the size or the rate of discharge of line currents although experience in any given territory may eventually lead to some such interpretation.

\section{RELATION OF ELECTRICAL RESISTIVITY OF EARTH -TO CORROSION}

While it has been generally recognized that the electrical resistivity of earth is one factor in the corrosion problem, its full significance is so masked by a host of other factors as to make its relation to the problem difficult of analysis. A review of the foregoing data on longline currents will show that wherever the soil resistivity drops to about $500 \mathrm{ohm}-\mathrm{cm}$, or lower, there is a sharp loss of current and pronounced pitting. Smaller values of current-density discharge occur in areas where the soil resistivity is 600 to $1,500 \mathrm{ohm}-\mathrm{cm}$, but as a rule the corrosion in such areas has not been acute. Illustrative of this is Figure 12, where the discharge zone coincides with a soil resistivity of about $1,300 \mathrm{ohm}-\mathrm{cm}$ or lower, but where destructive corrosion has occurred only where the resistivity is $600 \mathrm{ohm-cm}$ or lower. In Figure 14 there is a rather sharp line at $500 \mathrm{ohm}-\mathrm{cm}$ below which practically all of the corrosion trouble experienced on that line has occurred. In only one instance throughout the entire investigation was severe pitting encountered in any but soils of low resistivity. This condition was discussed under line ST.

Various methods for determining the corrosiveness of soils have been proposed from time to time, most of which involve resistivity in 
one form or another. None of these methods, however, are applicable to all soils, although some of them may apply roughly to soils of some particular type or even to several types. Although the most corrosive soils, as indicated by the tests of the National Bureau of Standards on buried specimens, are soils of low resistivity, severe corrosion has also occurred in some soils of relatively high resistivity. No satisfactory relation between earth resistivity and corrosiveness has been found which is applicable to all soils. However, a recent study of 22 of the soils in which the National Bureau of Standards has test specimens buried and on which six or eight year corrosion data were available at the time of the study, indicates that electrical conductivity is a rough index of the corrosiveness of alkaline soils or those in which the $\mathrm{pH}$ value is greater than 7.0. For acid soils, or those having a $\mathrm{pH}$ value less than 7.0, no such relation appears to exist, although it is possible that abrupt changes in conductivity in any one territory are indicative of a corrosive area. While it is not probable that a conductivity scale can be used as an index of corrosion for all soils, it is true that abnormally low resistivities in any type of soil are indicative of corrosiveness.

\section{STRAY CURRENTS}

On some of the pipe lines stray currents of measurable magnitudes were observed, but these did not seriously interfere with properly evaluating the galvanic component. Twenty-four hour smoked chart records showed these disturbances to be characteristic of interurban electric traction lines, and most pronounced during the mingt hours. Figure $15(a)$ is the record of the current flow on an 8 -inch oil line near Perry, Okla. The all-day average value of the current is 1.16 amperes. Peaks occur at $4.45,5.50$, and $6.35 \mathrm{p.m}$. Other disturbances occur throughout the night, with a fairly steady current during the working period of the day, between $S \mathrm{a} . \mathrm{m}$. and $4.30 \mathrm{p} . \mathrm{m}$. Figure 15 (b) shows a chart taken on the same line on a different day. The peaks have about the same displacement from each other as those in Figure $15(a)$ but occur at different times. The irregularity shown on the chart about $10 \mathrm{a} . \mathrm{m}$. is the result of starting the record at that time and removing it the next day at $9.15 \mathrm{a} . \mathrm{m}$.

Figure 16 (a) shows the current flow on an 8-inch oil line near Ponca City, Okla. Only slight disturbances resulting from stray currents were detected. These were not large enough to interfere with ob taining consistent results, throughout the working portion of the day.

Figure $16(b)$ is surprising in that it shows the same kind of disturbance on a 12 -inch oil line near Hearne, Tex., as occurred at Perry, Okla., some hundreds of miles distant. During the working portion of the day the disturbances are not serious.

A thorough canvas of the electric traction schedules in Oklahoma indicated that these disturbances originated near Tulsa, where large trains of cars are assembled by electric locomotives and moved from the oil fields. The large number of oil and gas lines extending from the Tulsa district to other parts of the State and into Texas are no doubt responsible for carrying the stray currents such great distances. 'The currents shown on the accompanying charts are of no practical significance, so far as corrosion is concerned, but may be objectionable on pipe lines near the power statiens where they originate. In some sections they may also be of sufficient magnitude to interfere seriously with a study of galvanic long line currents. 


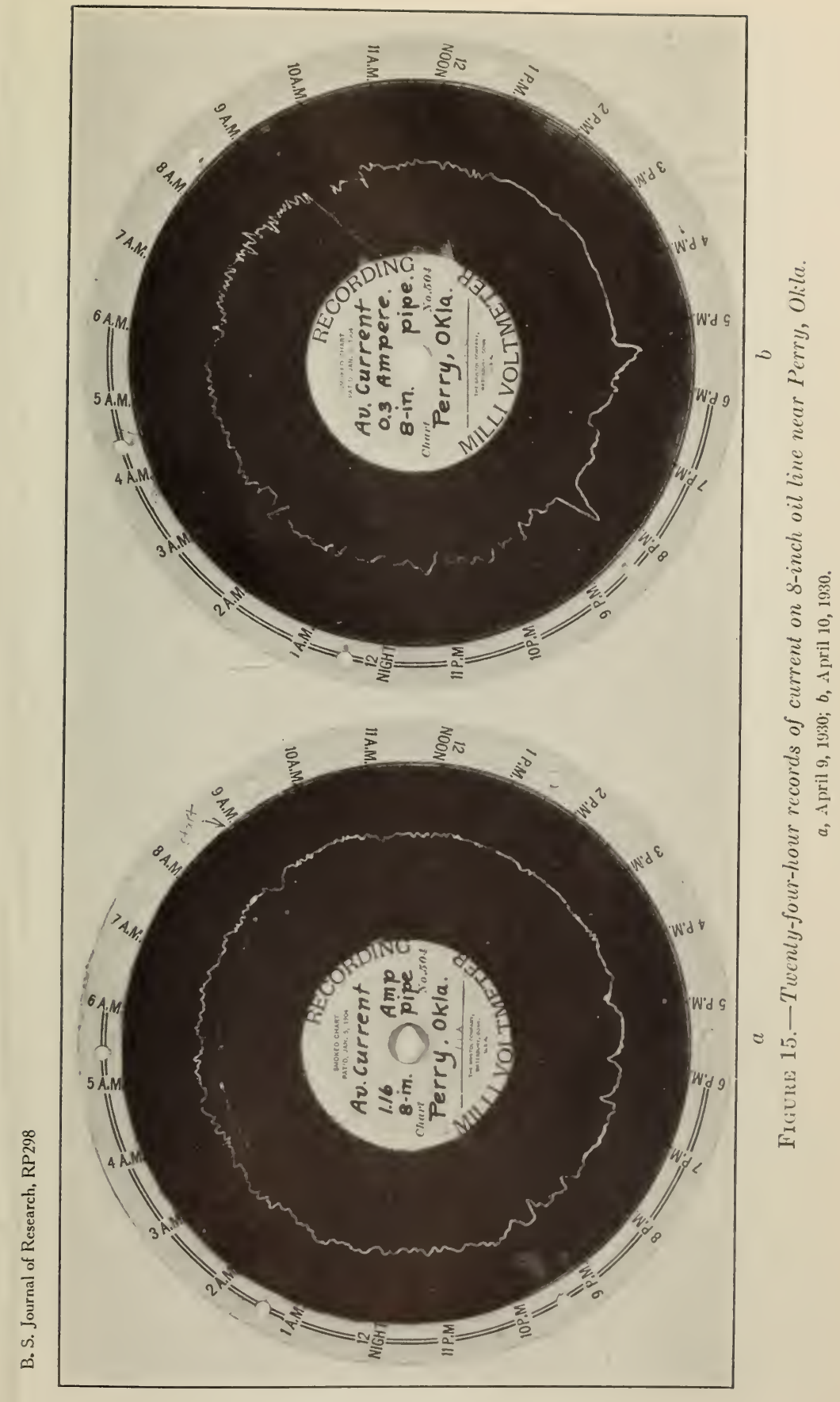




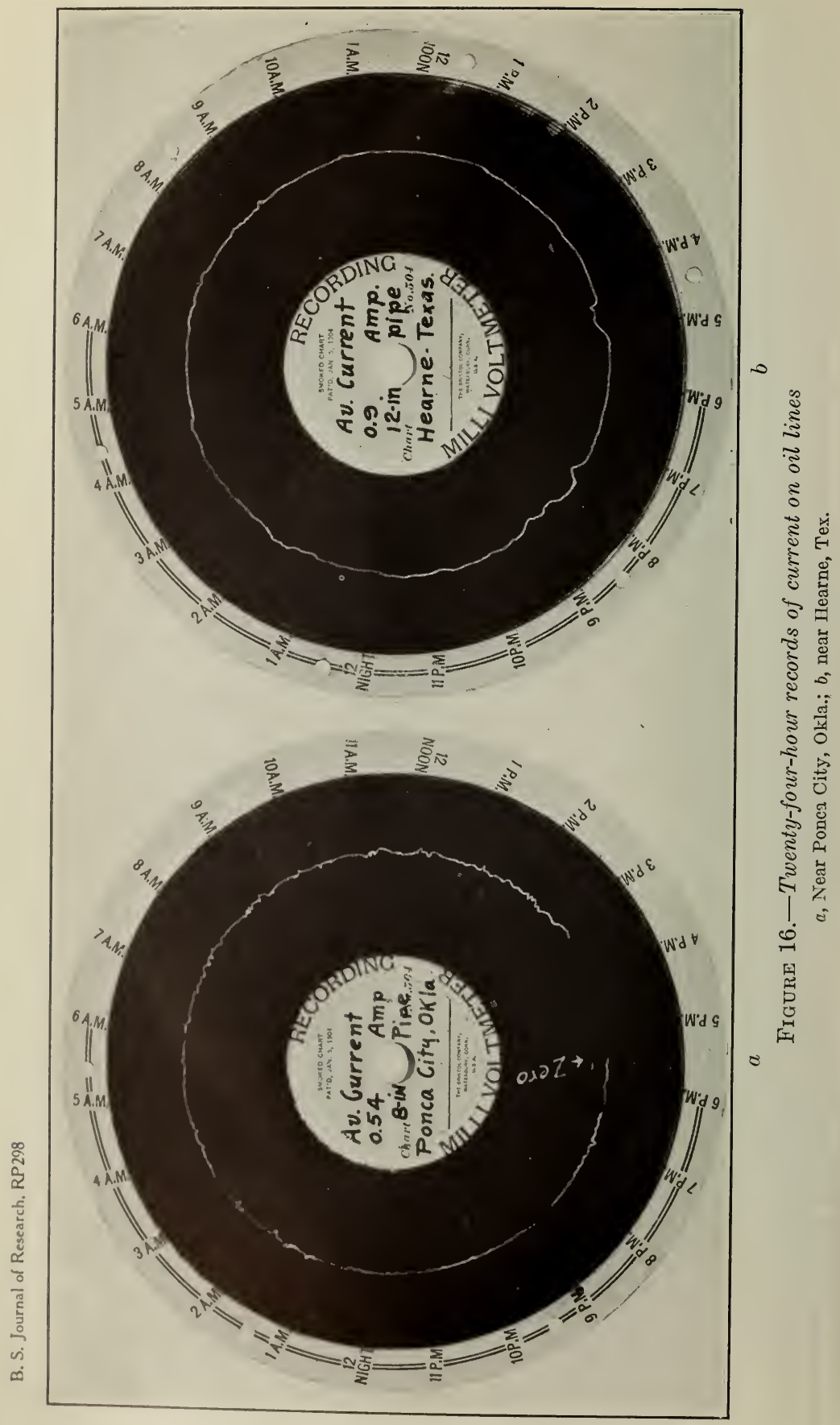


Other causes for observed variations in pipe line currents at any one point are not fully understood. One observer in California claims that he has good evidence to show that such variations are the result of static electricity produced by the action of the wind as it blows across ranges of hills. Magnetic storms are another possible source of variations.

\section{PRACTICAI SIGNIFICANCE OF DATA AND TECHNIQUE OF MAKING MEASUREMENTS}

The significance of the corrclations shown in this study are quite apparent to those who are concerned with the construction and protection of pipe lines. It has already been stated that the most recent tendency in pipe-line protection is toward the idea of selecting a coating to meet the particular requirements involved and away from a standard or uniform covering throughout the length of a line, irrespective of the character of the soil. The data herein justify this trend and suggest a practical means of carrying it into practice. They also support recent contentions ${ }^{3}$ that destructive corrosion of pipe lines is largely confined to local bad soil areas or "hot spots" of comparatively small extent. It can not be cxpected that the methods of survey here described are equally applicable to all types of soil. In some areas like the flat lands of the guilf coast the soil is so uniform that no useful information may be obtained from the measurement of line currents. However, in most rolling territory or where soil conditions are more variable, the study of line currents and soil resistivity affords a helpful means of locating the most corrosive soils. On existing lines both kinds of measurements are possible, while for projected lines or where, for any reason, current flow measurements are impracticable, it will be necessary to resort to the resistivity tests alone. For the benefit of those wishing to employ or experiment with these methods of soil survey a brief description will be given of the technique and apparatus employed in the investigations here reported.

\section{METHOD OF MEASURING LINE CURRENTS}

In using the current-flow method for locating corrosive areas measurements should be made at intervals of one-eighth to oncquarter mile, and when one of these sections shows a pronounced loss of current it should be further subdivided until the exact point where the current is leaving is located. Earth resistivity tests can then be made to ascertain the extent of the corrosive soil area.

The greatest problem involved in measuring pipe-line currents by the potential-drop method is that of making good electrical contact with the pipe. The potential differences to be measured are usually less than $1 \mathrm{mv}$ and this calls for a meter of high-volt sen sitivity. and, therefore, low resistance. Any resistance introduced into the circuit at the points of contact with the pipe will, therefore, affect the accuracy of the measurements. As rust is a poor conductor or even an insulator it is necessary to get through the rust film and makc contact with the solid metal of the pipe. Unless the pipe is uncovered, this is best accomplished by prodding or driving a bur to the top of the pipe and then inserting in the hole thus made a hardened steel point or drill. By turning or tapping the drili a good contact can usually

3 Chas. Fitzcerald, Corrosion and Pipe Line Coverings, Am. Pet. Inst., D. \& P. F. Bulletin No. 201, p. 126. I. A. Denison, Soil Characteristics and Currosion, Oil \& Ctas J.; June 5, 1939. 
be secured with but little difficulty. It is very important that the rod meet the pipe squarely on top where it will not creep down the side of the pipe when tapped with a hammer. More time is usually consumed in attempting to get good contact in a hole which is off center than is required to put down a new hole.

A low resistance millivoltmeter having a full scale range of $1 \mathrm{mv}$ is well adapted to this use. Both Gill and Putnam have successfully used a portable potentiometer. A standard millivoltmeter of the range indicated and having a resistance of about $3.4 \mathrm{ohms}$ was employed in the work here described.

1 standard test length of from 50 to 100 feet should be employed, and this distance can be indicated on one of the leads of the voltmeter which can then be used in lieu of a tape. Where the current is so large that the standard test length gives a deflection beyond the range of the meter, the section can be halved or otherwise subdivided. In fact it is a good practice to subdivide every test section or to make two independent measurements at each point on reconnaissance work. This procedure will enable the observer to catch any error resulting from high resistance joints in the pipe line or from poor contacts. Screw couplings in pipe lines usually have the same resistance per foot as the solid pipe, but occasional ones of abornomally high resistance are encountered and these must be guarded against. It is, of course, necessary to make correction for the resistance of the voltmeter leads. This correction can be combined with the other constants involved to arrive at a conversion factor by which the current can be easily computed from the meter reading.

Let

$W=$ weight of pipe in pounds per foot.

$L=$ length of test section in feet.

$R=$ resistance of voltmeter in ohms.

$r=$ resistance of leads in ohms.

$s=$ resistivity of pipe material in microhms per pound-foot. For steel pipe, National Tube Co. tables, 1913, give $s=215.8$. For wrought-iron pipe, Byers' table weights give $s=209.3$.

$e=$ reading on meter in millivolts.

Then, the current in amperes will be

$$
i=\frac{1,000 W(R+r)}{R s L} \times e
$$

For the following constants:

$$
\begin{aligned}
W & =28.55 \text { pounds ( } 8 \text {-inch stcel pipe). } \\
L & =75 \text { feet. } \\
R & =3.4 \text { ohms. } \\
r & =0.35 \text { ohm }(85 \text { fect of No. } 16 \text { lamp cord). } \\
s & =215.8 \text { (steel pipe). } \\
i & =\frac{1,000 \times 28.55 \times 3.75}{3.4 \times 215.8 \times 75} \times e=1.95 \mathrm{e} .
\end{aligned}
$$

In like manner the conversion factor for any set of conditions can be derived.

The sample dat a sheet shown on opposite page was submitted by one of the pipe line companies which assisted in this investigation and uhich has since carried on an independent study of line currents and soil resistivity along its own lines with considerable success. 
矛

1
1
0
0
0

हूํํำ

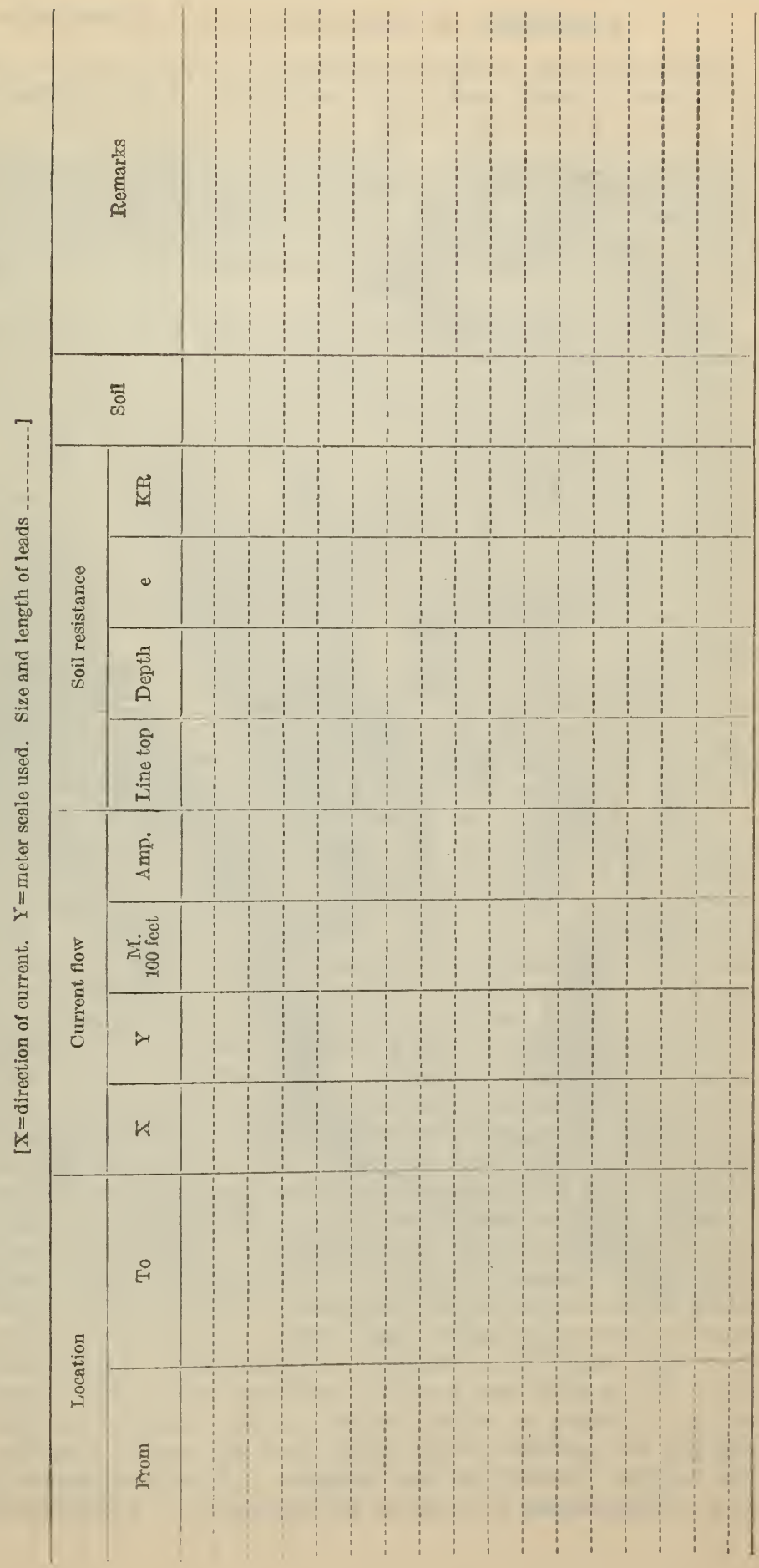




\section{METHOD OF MEASURING SOIL RESISTIVITY}

When accurate results are desired it is customary to measure the resistance of earth and other electrolytes with alternating current, in order to avoid polarization and other effects inherent in methods employing direct current. However, by employing a suitable range of current density and voltage, and by taking readings immediately after the circuit is closed or before polarization has set in to any great extent, it is possible in most soils to obtain by direct-current measurement results closely approximating the actual resistance of the medium.

Because of the extreme simplicity of the direct-current equipment and the greater speed with which it can be used in the field this method was employed in making soil resistance tests in this investigation. The first apparatus consisted of a rectangular cell made of insulating material and provided with metal end plates. This cell was 1 inch square in section and 2.54 inches long, between the end plates. In such a cell, which has a cross section of $6.45 \mathrm{~cm}^{2}$ and a length of $6.45 \mathrm{~cm}$. the actual resistance in ohms of a prism of earth between the end plates is numerically equal to the resistivity of the earth in ohm-centimeter. The resistivity of a medium is the resistance iil ohms between two parallel faces of a centimeter cube of that medium.

This cell was packed full of earth and connected in series with two dry cells and a small pocket voltmeter. The deflection on the voltmeter was observed immediately after pressing the key or before polarization had greatly diminished the reading. The resistivity of the earth was then calculated from the constants of the apparatus.

As the work progressed and the significance of earth resistivity became more apparent, the need for a more rapid method of making these tests was seen. Accordingly, two metal tipped oak rods were constructed with the voltmeter mounted on one and a small flash light battery on the other, as shown in Figure 17. Wires leading from the metal ferrules, through channels in the rods to the voltmeter and battery, respectively, and a connection between the battery and meter completed the test set. These rods are pushed into the earth to any desired depth and a reading obtained by pressing the voltmeter key. The resistance in ohms between the electrodes is then calculated as before. To obtain the resistivity of the earth the constant for the apparatus must be known. This constant depends on the area and shape of the metal electrodes and distance between them and can be obtained by calibrating them in a medium of known resistivity. The resistance between the tips of the rods shown in the figure is practically independent of the distance between them, provided it is about 8 inches $(20 \mathrm{~cm})$ or more. More recent development work on this piece of apparatus has shown that iron electrodes develop less polarization than brass or copper electrodes, although more care must be exercised in keeping them bright and free from rust. Since with iron or other ordinary base metal electrodes polarization is largely a cathode efiect, it can be reduced still further by making the cathode much larger than the anode, thereby decreasing the current density on the cathode. A low-resistance meter, such as a milliammeter is found to bo preferable to a high-resistance volt- 


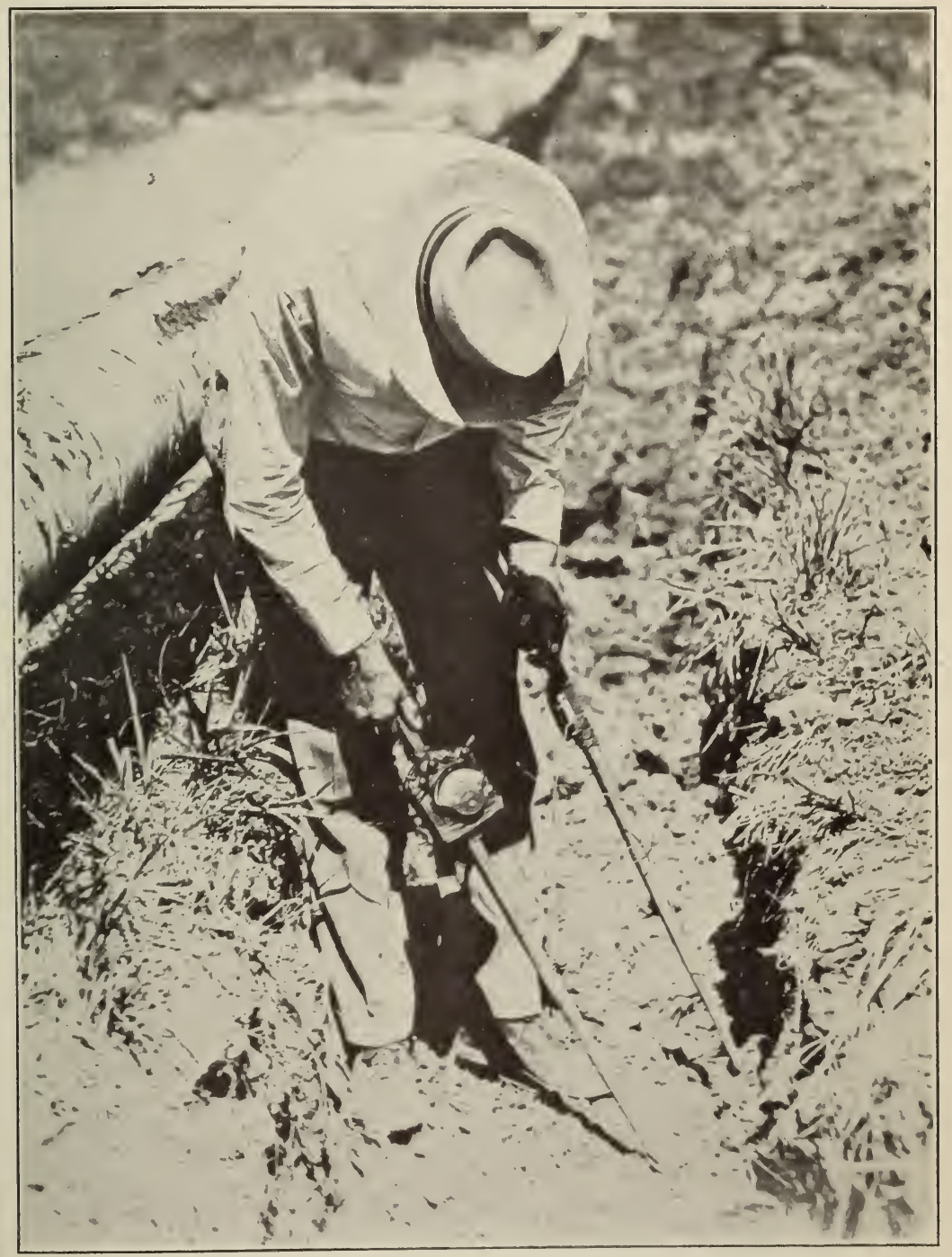

Figure 17.-Apparatus for measuring electrical resistivity of carth 
meter, as with the former practically the full voltage of the test battery is applied between the electrocies, irrespective of the meter reading, while with the latter a large part of the battery voltage is consumed within the meter itsclf. This is particularly objectionable in low-resistance soils where a large deflection on the meter is recorded, and, therefore, where the potential between the electrodes is correspondingly smail and polarization effects are relatively large.

An instrument of the following description has been found to givo satisfactory results and gives values of the resistivity of sodium chloride solutions ranging from 100 to $10,000 \mathrm{ohm}-\mathrm{cm}$ with an accuracy of about 6 per cent as compared to a.c. bridge determinations. The anode is an iron cone of one-half inch $(12.8 \mathrm{~mm})$ base and one-quarter. inch $(6.3 \mathrm{~mm})$ height. The cathode, also of iron, is a frustrum of a cone $2 \frac{5}{8}$ inches $(6.7 \mathrm{~cm})$ long, $3 / 4$-inch $(1.9 \mathrm{~cm})$ lower base, $1 / \mathrm{s}-$ inch (3 mm) upper base. The point is ground or turned on a 1/16-inch $(1.5 \mathrm{~mm})$ radius. A three-volt battery of two flash-light dry cells is used, the positive pole being connected through a switch to the smaller electrode or anode. A milliammeter having ranges of 25 and of $100 \mathrm{~m}$. a. is employed, the $25 \mathrm{~m}$. a. range is good for resistivities down to about 370 ohm-cm while the $100 \mathrm{~m}$. a. range is good for resistivities between 400 and $100 \mathrm{ohm}-\mathrm{cm}$. The scale of the meter can be graduated directly in ohm-centimeter. A multiplier coil is also included in the meter by which the voltage of the battery can be checked from time to time. The calibration constant for such an instrument is approximately 3 ; that is, the soil resistivity in ohmcentimeters is equal numerically to three times the incasured resistanco between the electrodes when they are separated in the oarth about 8 inches $(20 \mathrm{~cm})$, or more.

This apparatus permits of making frequent and rapid tests of earth resistivity along a pipe line or along a projected pipe line. Although it is not claimed that absolute values of resistivity arc obtained with this apparatus, the results are sufficiently accurate for all practical purposes, provided the soil is not too dry. It is important to test the earth at pipe level and where there is sufficient moisture to afford nearly maximum conductivity. Measurements should pol be made in dry soil as they will mean nothing, even though an indication on the meter is obtained. Damp soil which will pack in the hand will usually show a conductivity approaching that of a saturated condition. It is therefore necessary to confine measurements to wet, or at least to damp soil. Access to the desired depth can be obtained by driving a steel bar to make a hole or by using a soil auger. Where the ground is not too hard a depth of 18 inches or 2 feet can be attained by removing the top soil with a shovel and pushing the rods into the soft earth.

The intervals at which such tests should be made wiil depend upon the character of the soil and, perhaps, many other factors. To be sure that no extensive hot spots are missed, it may be necessary in some locations to make tests at intervals of 100 feet or less, while in other areas the vegetation and topography may be depended on to a large extent to indicate the character of the soil. 


\section{SUMIMARY}

1. Much of the soil which is exceptionally corrosive to ferrous materials exists in the form of naturally occurring outcrops or pockets in which the soluble salt content is abnormally high. Although relatively small in extent, such areas account for a large proportion of the corrosion on underground pipe systems. The predetermination of these corrosive areas is a matter of great importance to the pipe owners, both from the standpoint of protecting new lines and the reconditioning of old ones.

2. Practically all pipe lines carry galvanic electric currents of measurable magnitudes and these bear a worthwhile relation to both corrosion and the electrical resistivity of the soil.

3. In general, galvanic electric currents collect on pipe lines in regions of normal or high-soil resistivity and discharge from the lines in relatively smali areas of low-soil resistivity.

4. At points of abrupt discharge and abnormally low-resistivity corrosion is most severe.

5. Soil resistivities of about $500 \mathrm{ohm}-\mathrm{cm}$ or less are usually indicative of severe corrosion. Above about $1,000 \mathrm{ohm}-\mathrm{cm}$ there appears to be little relation between resistivity and corrosion.

6. The measurement of pipe-line currents and soil resistivity offers a helpful means of locating exceptionally corrosive soil areas.

Washington, February 7, 1931. 